\title{
TLR3 agonists: RGC100, ARNAX, and poly-IC: a comparative review
}

\author{
Asma Komal ${ }^{1} \cdot$ Mamoona Noreen $^{1}$ (1) $\cdot$ Attalla F. El-Kott ${ }^{2,3}$ \\ Received: 25 January 2021 / Accepted: 10 May 2021 / Published online: 19 June 2021 \\ (c) The Author(s), under exclusive licence to Springer Science+Business Media, LLC, part of Springer Nature 2021
}

\begin{abstract}
Toll-like receptors 3 (TLR3) have been broadly studied among all TLRs over the last few decades together with its agonists due to their contribution to cancer regression. These agonists undeniably have some shared characteristics such as mimicking dsRNA but pathways through which they exhibit antitumor properties are relatively diverse. In this review, three widely studied agonists RGC100, ARNAX, and poly-IC are discussed along with their structural and physiochemical differences including the signaling cascades through which they exert their actions. Comparison has been made to identify the finest agonist with maximum effectivity and the least side effect profile.
\end{abstract}

Keywords Toll-like receptor $\cdot$ TLR3 $\cdot$ Agonists $\cdot$ RGC100 $\cdot$ ARNAX $\cdot$ Poly-IC

\section{Introduction}

Toll-like receptors (TLRs) are a family of pattern recognition receptors (PRRs) that play a crucial part in the commencement of responses of the innate immune system by sensing conserved pathogen-associated molecular patterns (PAMPS) for early recognition of a particular pathogen and recruiting the innate immune cells such as monocytes, dendritic cells, and macrophages [1,2]. This family comprises ten members in humans and thirteen in mice $[3,4]$. The typical TLR is a type I transmembrane protein consisting of three structural domains: a leucine-rich repeats (LRRs) motif that plays a vital part in the recognition of a pathogen, the toll-interleukin 1 receptor (TIR) domain for interaction

Asma Komal and Mamoona Noreen have contributed equally.

Mamoona Noreen

mamoona.noreen@gmail.com

Asma Komal

asmakomalmsc@gmail.com

Attalla F. El-Kott

elkottaf@yahoo.com

1 Department of Zoology, The Women University Multan, Multan, Pakistan

2 Department of Biology, College of Science, King Khalid University, Abha, Saudi Arabia

3 Department of Zoology, Faculty of Science, Damanhour University, Damanhour, Egypt with signal transduction adaptors, and a transmembrane domain [5].

TLR3 is mainly expressed in neuroectodermal and myeloid cells. TLR3 of myeloid cells favorably acts as a receptor for the surface recognition of viral double-stranded RNA [6]. The worth of dsRNA in oncology has been assessed by randomized trials carried out in the 1990s. The reproducible effects observed in patients suggest dsRNA to be remarkably effective in the subsection of individuals that remained to be determined. Identification of TLR3 as the exclusive target of dsRNA along with the portrayal of its expression in cancer cells led researchers to conclude that TLR3 expressed by cancer cells is highly sensitive to dsRNA [7].

Since then many TLR3 agonists have been designed to mimic the dsRNA and have been studied indicating that numerous mechanisms subsidize the efficacy of TLR3 agonists. A novel therapeutic approach involves aiming TLR3 receptor expressed by tumor cells to induce apoptosis. It directly interferes with the progression of cancer especially in patients that have a compromised immune system. TLR3 is being widely studied by oncologists all over the world since its significant role in antiviral immunity has been discovered. Currently, its agonists are being exploited in vaccine development. Several non-clinical, preclinical, and clinical studies have inspected the potential of these agonists as adjuvants [8].

In this review comparison of three of the extensively studied TLR3 agonists RGC100, ARNAX, and polyinosinic:polycytidylic acid (poly-IC) along with their 
dissimilar pathways contributing to tumor regression has been made.

\section{TLR3 expression}

TLR3 is expressed both intracellular and on the cell surface by guard cells of the innate wing of the immune system (macrophages and dendritic cells) [9]. Apart from immune cells, it is also expressed on the cell surface of other cells such as epithelial cells and fibroblasts [10]. T cells minimally express TLR3 though expression can be upregulated by T cell receptor cross linking, whereas neutrophil do not express it at all $[11,12]$. Viral infection in both mouse and human dendritic cells (DCs) results in upregulation of TLR3 expression. On the contrary, Lipopolysaccharide (LPS) merely up-modulates TLR3 expression in murine cells [13]. DCs when stimulated with dsRNA tend to induce the relocation of the receptor to endosomes from the endoplasmic reticulum (ER) [14].

\section{TLR3 signaling pathway}

TLR3 activation by extracellular dsRNA occurs after its recognition in a sequence-independent manner. TLR3 identifies dsRNA through its ectodomain (ECD), resulting in dimerization of receptors which is mandatory for signal transduction [15]. TLR3 recruits a defensive feedback towards dsRNA viruses for instance poliovirus, encephalomyocarditis virus, coxsackievirus group B, and serotype 3 including DNA virus infections (murine cytomegalovirus and herpes simplex/HSV1) [16-18]. Moreover, TLR3 can also identify transcribed dsRNA along with its synthetic analogs, such as polyadenylic-polyuridylic acid (poly A:U). Considering this, several studies have been conducted to imitate the response to RNA virus infection by using such synthetic analogs.

The signaling cascade interceded by TLR 3 commences in the endosomal compartments with a low $\mathrm{pH}$ environment [19]. Current evidence has revealed that apart from spotting dsRNA, the proinflammatory response is also triggered by cell membrane-bound TLR3 in a predominant manner [20]. The capability of foreign RNAs to trigger cellular responses is largely dependent on the mode of their entry into the cells as well as on their stability in the extracellular environment. Compared to single-stranded RNA, dsRNA is impervious to degradation; hence, the viral dsRNA from infected cells can lead to activation of surrounding cells which are uninfected, resulting in the formation of an antiviral state. The dsRNA can enter cells through Raftlin-mediated clathrin-dependent endocytosis [21] or via apoptotic bodies internalization [22] or through complex formation with the LL-37, an antimicrobial peptide, through formyl peptide receptor type 1 ( FPRL-1) [23].
TLR3 signaling is commenced by dimerization of TLR3 receptors. Once the TLR3-dsRNA species has been formed in the endosome, later tyrosine kinases epidermal growth factor receptor (EGFR), and Src collaborate in order to phosphorylate TLR3 [24] [25]. Afterwards, the Toll/IL-1 receptor (TIR) domain of TLR3 involves TIR domaincontaining adapter-inducing interferon- $\beta$ (TRIF) and TRIF-related adaptor molecule (TRAM). TLR3 is the only member that recruits TRIF unswervingly towards the TIR domain in order to start signaling cascade, whereas TLR4 can signal independent of MyD88 through TRIF [26] but it entails the spanning adaptor TRAM. Recruitment of TRIF to TLR3 is thought to be the stage that injunctions downstream signaling cascade. This activates the TANK-binding kinase-1 (TBK-1) which results in phosphorylation of the transcription factor interferon regulatory factor 3 (IRF3) [27]. Recruitment of TNF receptor-associated factor 3 (TRAF3) connects TRIF and the complex of TBK-1 kinase. IRF3 after phosphorylation is translocated into the nucleus where it is responsible for activation of certain target genes (proinflammatory) most significantly type I interferons (IFNs-1) [27]. TLR3 signaling through TRIF also results in NF- $\mathrm{KB}$ activation [28, 29]. NF- $\mathrm{KB}$ chain of TLR 3 cascade is initiated by TRIF-dependent conscription of 2 distinct cascades that are facilitated by receptor-interacting protein (RIP1) [30] or TRAF6, both of these congregate on transforming growth factor $\beta$-activated kinase 1 (TAK1) and IкB kinase (IKK) complex. TAK1 phosphorylates IKK $\alpha$ and IKK $\beta$, leading to phosphorylation of $\mathrm{I} \kappa \mathrm{B}$; the NF- $\kappa \mathrm{B}$ inhibitor, resulting in the dilapidation of IK $\beta$ and the translocation of NF- $\kappa B$ into the nucleus [31, 32]. Eventually, numerous factors involved in transcription for instance IRFs and cAMP response element-binding protein (CREB) are activated and translocated into the nucleus. In the nucleus, they bind to their corresponding elements in the promoter region of the target genes (IFN- $\beta$ IL-6, IL-12, and CCL3) [33]. TAK1 and signaling adaptors also activate mitogen-activated protein kinase (MAPKs) and c-Jun N-terminal kinases (JNK). MAPK autoactivates on interaction with TAK1-binding protein 1 [6], stimulating activator protein 1(AP-1), which encourages transcription of cytokines and chemokines. Generally, the most noteworthy consequence of all three segments of TLR3 signaling is the provocation of molecules that cause inflammation, including chemokines (CCL2 and CXCL8), proinflammatory cytokines (TNF and IL-1), endothelial adhesion molecules, and type I IFNs vital for responses against viruses. Besides prompting an inflammatory response, dsRNA provokes apoptosis in numerous mammalian cell lines via distinct routes. 


\section{TLR3 agonists}

TLR3 agonists are not only being employed as adjuvants for antigen-peptide vaccination but are also being used along with radiotherapy [34]. The antitumor responses brought by TLR3 agonists are accredited to their competence to stimulate DCs, which when stimulated lead to activation of tumor-specific $\mathrm{T}$ cell responses and also to their ability to shift the phenotype of tumor-associated myeloid suppressor cells and macrophages from immunosuppressive to immunosupportive [35-37]. TLR3 is expressed in various kinds of cancers, including breast cancer, ovarian cancer, cervical cancer, hepatocellular cancer, prostate cancer, adenocarcinoma, head and neck cancer, oral cell squamous and esophageal cancer, lung squamous cell cancer, and skin cancer [38]. Similar to healthy cells, cancer cells also retort to TLR3 ligands by secreting inflammatory cytokines, chemokines, and type I IFNs which augment immune cell conscription and activation. Furthermore, inhibition of tumor progression in numerous mouse and human cancer cell models has been observed. Cell death via apoptosis and diminishing proliferation are two mechanisms by which TLR3 agonists limit tumor growth [38].

\section{RGC100}

A novel TLR3 agonist RGC100 has been studied by many researchers mainly because of its unique structural properties such as solubility and homogeneity including its distinct chemical structure, length (100 bp), and MW (64.9 KDa) [39]. Its precise chemical structure and solubility play a key role in reducing the potentially toxic effects that are caused by other TLR3 agonists such as poly-IC [40].

Furthermore, due to its serum stability, it can activate dendritic cells by targeting endosomal TLR3 specifically. The improved serum stability of RGC100 is attributed to its $100 \%$ GC content. Through experimental data, it has been exposed that these sequences have tightly stacked bases in the dsRNA structure which subsequently increases duplex stability [41]. This increases the half-life of dsRNA. For example, wrapped nucleic acids improve the resistance of dsRNA to serum nucleases [42]. Moreover, serum stability can also be improved by chemical modifications in its ribose backbone [43].

Another significant advantage of RGC100 is that it can refine its potency for activation of immune cells by fluctuating the dsRNA compound length. It has been stated previously [44] that in vivo activation of the TLR3 pathway is dependent on the length of dsRNA not the sequence of nucleotide. Henceforth, RGC100 offers the option to tune the selectivity index with regard to its immunological effectiveness and toxicity for a specific indication.
RGC100 proficiently kindles the release of TNF- $\alpha$, IL- 6 , and IL- $1 \beta$ by CD1 $\mathrm{c}^{+}$DCs and boosts their ability for the proliferation of T cells. Due to its exceptional features, RGC100 may be considered a capable candidate for therapeutic vaccination and prophylactic strategies against pathogens and tumors.

\section{Poly-IC}

Poly-IC is a synthetic analog of dsRNA and an agonist of TLR3 and retinoic acid-inducible gene I/RIG-I like receptors (RLRs), including RIG-I and melanoma differentiation-associated protein 5 (MDA5). Its role in cancer immunotherapy has been discovered well over the last few years. It activates the innate immunity, later ensuing regulation of adaptive immune system [6, 45-48] resulting in adjustments in the microenvironment of tumor and prominent clampdown of tumor growth [48].

Study shows that tumor metastasis in immunodeficient mice can be reduced upon transfection with poly-IC. This is indicative of the fact that the antitumor effect mediated by poly-IC does not involve immune system activation [49]. Furthermore, poly-IC can also directly prompt cancer cells to undergo apoptosis [50].

Cell-associated form of poly-IC is labeled to be much more effective in activating TLR3 when compared to soluble dsRNA, which suggests that dsRNA from dying cells is possibly a more puissant and functionally pertinent TLR3 ligand when compared to dsRNA from living cells [51].

Upon detection of poly-IC, TLR3 signals through TRIF adaptor also identified as TICAM1 which initiates a downstream signaling cascade that results in activation of an analogous array of transcription factors such as IRF1, IRF7, IRF3 and NF- $\mathrm{KB}$. These factors result in the induction of gene expression that encode type I IFNs, proinflammatory cytokines and numerous molecules that are involved in antigen presentation [47]. Poly-IC induces DC maturation, enhancing their capacity to prime and increase antigenspecific T cell responses [52-54]. Poly-IC is particularly a promising adjuvant for cancer vaccination due to its DC stimulatory activity. It must overcome its lenience to selfantigens associated with cancer and the immunosuppressive impact.

Together with tumor-associated antigen peptides, it effectively induces antigen-specific cytotoxic $\mathrm{T}$ lymphocyte (CTLs). In numerous cancer patients, tumor reduction was detected after immunotherapy in clinical phase trials [55]. But, a majority of the clinical studies were halted due to noxious unbearable manifestations. Lethal side effects included kidney failure, hypotonic shock, and thrombosis which are signs of cytokinemia [56].

Other drawbacks of poly-IC include its vague structure and weak homogeneity [57]. Poly-IC consists of ssRNA 
Fig. 1 Schematic representation of TLR3 pathway. Poly-IC stimulates TLR3 which generates TRIF-dependent response by the conscription of TRIF to the cytoplasmic domain which then allows binding of TRIF to RIP1, TRAF6, TBK1 and TRAF3 resulting in activation of MAP kinases and IKK complex. MKK1/2, MKK3/6, and MKK $4 / 7$ activate ERK, JNK and p38, respectively and I $\mathrm{B} \alpha$ degradation releases NF- $\kappa$ B. TBK1 phosphorylates IRF3 and 7. Nuclear translocation of NERK, JNK and p38 occurs which activates the transcription factor AP-1, and NF- $\mathrm{B}$, IRF-3 and IRF-7 translocate to the nucleus. AP-1 and NF- $\mathrm{B}$ bind to the promoter regions of cytokine genes while IRF-3 and IRF-7 including NF- $\mathrm{KB}$ bind to the promoter region of chemokine genes and induce their transcription

and dsRNA mix molecules ranging from 1.5 to $8 \mathrm{~kb}$ [58] defectively joined as dsRNA or ssRNA, mostly due to restricted solubility and problematic re-formation of polyIC that involves heating at $50-60{ }^{\circ} \mathrm{C}$ and slow cooling for several hours to attain rejoining of both poly(I) and poly(C) strands. Consequently, toxicity ranging from hypersensitivity to coagulopathy, kidney failure, and heart failure has been reported in many trials [59]. An additional problem of poly-IC is its short half-life which results in its quick RNase-mediated degradation in body fluids [43, 60] (Fig. 1).

Poly-IC12U Poly-IC12U is an altered form of poly IC, comprising of incompatible residues of uracil and guanosine. PolyIC12U was made in order to vanquish the toxicity problems related to poly IC. The mismatches in the backbone of molecule result in reduction of its half-life. The reduced half-life is the reason why poly-IC12U doesn't incite antibodies in response to ds nucleic acids. Poly-IC12U signals solely through TLR3 receptor and not MDA-5. However, it induces type 1 IFNs, though to lesser absolute levels as compared to poly-IC. Moreover, poly-IC12U elicits the production of $2^{\prime}, 5^{\prime}-\mathrm{OAS}$ an antiviral effector upstream of the endoribonuclease's activation. The upregulation of major histocompatibility complex (MHC) Class I or II molecules, CCR7, CD40, CD83 and CD86 show that polyIC12U is capable to activate DCs. Human DCs stimulation with polyIC12U is extremely sensitive to treatment. The outcomes of studies differ that compared IL-6, IL-10, and IL-12 release after poly IC and poly-IC12U administration [61].

\section{Poly-ICLC}

Poly-ICLC is poly-L-lysine in carboxymethylcellulose which is a synthetically derived form of poly-IC. It is made by combining poly-I-poly-C mixture and poly-L-lysine in CMC. The novel molecule has evidently improved resistance to nucleolytic hydrolysis, thus extending and boosting its activity, ensuing induction of cytokines, chemokines, and interferons besides upregulation of costimulatory molecules. Poly-ICLC induces a strong Th1 phenotype categorized by the induction of IL-6, IL-12, TNF- $\alpha$ IFN- $\gamma$ and type 1 IFN, in addition to the chemokines $\mathrm{KC}$, monocyte chemoattractant protein-1 (MCP1), macrophage inflammatory protein 1 (MIP1- $\alpha$ and MIP1- $\beta$ ) (Table 1).
Table 1 Poly-IC and its derivatives

\begin{tabular}{llll}
\hline & Poly-IC & Poly-ICLC (Hiltonol) & Poly-IC12U (Ampligen) \\
\hline Targeted receptors & MDA-5, TLR3 & MDA-5, TLR3 & TLR3 \\
Immune profile & Th1 & Th1 & Th1 \\
Resistance to serum nucleases & Not resistant & Resistant & Not resistant \\
Relative stability & ++ & +++ & + \\
\hline
\end{tabular}




\section{ARNAX}

An effort to overcome the deadly demonstrations triggered by poly-IC was to diminish its toxicity. Cytokine toxicity was mainly attributed to the MAVS pathway $[62,63]$. Direct DC maturation and IL-12p70 production are crucial for the antitumor function of poly-IC. This outcome is not dependent on the MAVS signal. Henceforth, the problem could be resolved by developing a compound that precisely activated TLR3.

Several markers were monitored to design a ligand specific for TLR3 that satisfactorily triggered the TICAM-1 pathway only. These compounds were laboratory transcribed RNA 50 capped with phosphorothioated GpC. sODN capping that impeded activation of RIG-I and expediated dsRNA relocation to endosomes [63]. This synthetic DNA-dsRNA hybrid compound was named ARNAX which contained dsRNA (sequence of measles virus) so that it does not induce RNAi in human transcripts. The short $120 \sim 140$ bp length of the RNA chain is enough to activate MDA5 but cannot trigger the activation of TLR3.

Its conjunction sites of DNA-RNA and dsRNA regions show resistance to serum nucleases [64].

dsRNA is directed to TLR $3^{+}$cells where it is endocytosed by the GPC ODN cap after activating TLR3 [21]. Instigation and signal transduction of TLR3-TICAM-1 cascade necessitates dsRNA which has a length greater than 90 bp [39].

The poly-IC analog of viral dsRNA, additionally activates MDA5 [65, 66] which results in unnecessary inflammation by type-I IFNs/cytokines production. Compared to poly-I:C, ARNAX instigates negligible inflammatory IFN- $\beta /$ cytokine production in a TLR3-TICAM-1-dependent manner, revealing that the TLR3-TICAM-1 pathway causes an insignificant and localized release of cytokines for priming DCs. Moreover, IL-12 (Th1-type cytokine) is considerably triggered by ARNAX in a TLR3-dependent way when injected subcutaneously in mice [67]. Th1-slanting profile and noninflammatory characteristic of ARNAX can be ascribed to early endosome localization and delimited expression profile of TLR3 along with the TICAM-1 signalosome composition [68].

TLR3 pathway is crucial for ARNAX adjuvanticity for antibody production. ARNAX activates antibody presenting dendritic cells to cross-present cytotoxic $\mathrm{T}$ cells [69]. This cross presentation involves TLR3-TICAM-1-IRF3-IFN- $\beta$ signaling axis [70]. Signaling adaptor of RIG-I-like receptors, i.e., mitochondrial antiviral-signaling protein (MAVs), adaptor of the majority of TLRs except for TLR3 (MyD88), and adaptor of DNA sensors, i.e., stimulator of interferon genes (STING) do not play any role in ARNAX-induced $\mathrm{CD} 8^{+} \mathrm{T}$ cells cross priming [71]. Moreover, localized production of IFN- $\beta$ interceded by DCs is enough for the cross presentation of cytotoxic T cells [70, 72, 73].

ARNAX also boosts antitumor outcome through programmed death-ligand 1 (PD-1/L1) impediment (Fig. 2). $\mathrm{PD}-1 \mathrm{Ab}$ solely upgrades tumor-killing proficiency and proliferation of cytotoxic lymphocytes. Consequently, resistance to PD-1/L1 Ab therapy is the mark of CTL dysfunction in a tumor. Furthermore, when CTL proliferation is lacking, therapy with PD-1/L1 Ab is not effective. Syndication of CTL-induced vaccine therapy with PD-1/L1 Ab therapy is one of the actions that can be taken to ameliorate postoperative cancer results with PD-1/L1. The effect of PD-1/ L1 Ab therapy can be improved through endogenous tumorassociated antigen (TAA) and ARNAX with very few side effects $[74,75]$.

\section{Vaccine adjuvant uses of TLR3 agonists}

\section{RGC100}

Through gene silencing experiments, it has been observed that RGC-100 signaling through TLR-3 results in activation of mouse and human myeloid dendritic cells. This activation leads to the release of proinflammatory
Fig. 2 ARNAX signaling pathway. ARNAX activates TLR3 but not cytoplasmic MDA5/ RIG-I. The TLR3-TICAM-1IRF3-IFNAR signaling axis is crucial in dendritic cells for ARNAX-mediated cytotoxic T lymphocyte (CTL) induction

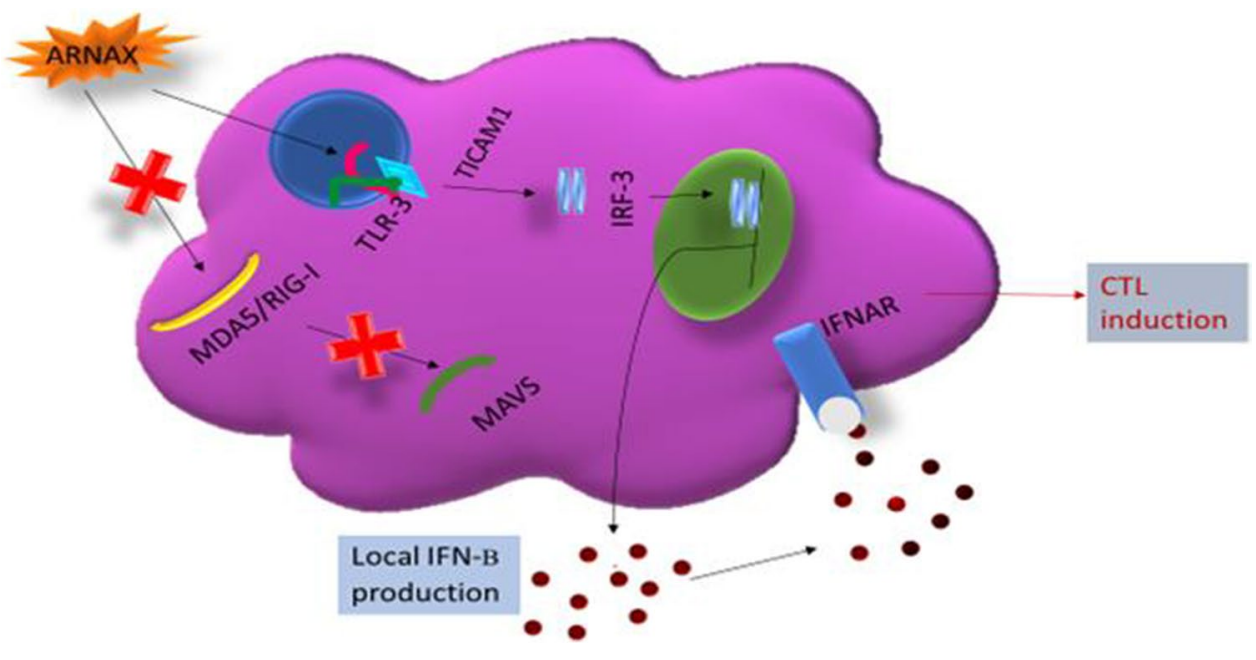




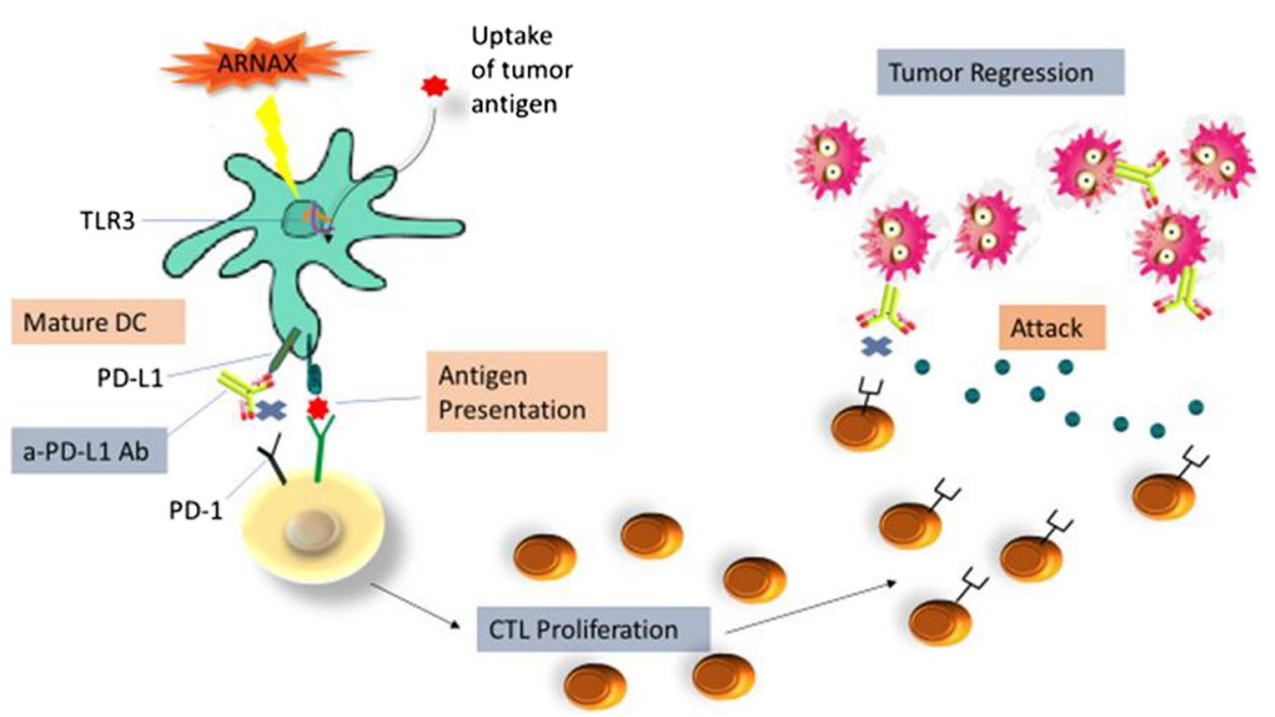

Fig. 3 Antitumor response via inducing a PD-1/L1 obstruction. ARNAX therapy enhances antitumor responses in conjunction with PD-1/PD-L1 blockade. Tumors fundamentally lack adjuvant due to which DCs remain immature state and fail to induce tumorassociated antigen (TAA)-specific CTLs. ARNAX activates TLR3 in

cytokines. Additionally, RGC100 increases the capability of CD1c ${ }^{+}$DCs to trigger the proliferation of T-cells. These immunostimulatory characteristics represent RGC100 as a hopeful adjuvant for prophylactic and therapeutic vaccination strategies [76].

\section{ARNAX}

It has been found that after ARNAX vaccination inflammation occurs independent of immune stimulation. ARNAX forecasts that the infection-DC maturation axis is autonomous of the in vivo infection-cytokinemia axis. ARNAX enhances the antitumor response in mouse-implant models by targeting both hosts as well as tumor cells. In order to improve the tumor microenvironment, it is significant to find such non-inflammatory adjuvants [77].

\section{Poly-IC and its derivatives}

The Th1 profile which has been linked with poly-IC has made it an outstanding adjuvant for vaccines that are known to require a T-cell component. Poly-IC along with its derivatives has been unswervingly publicized to be among the sturdiest Th1-stimulatory adjuvants [54, 78, 79]. Some of the vaccine adjuvant uses have been described in Table 2 .

\section{Comparison}

Foreign RNA patterns can be functionally classified into two: first, which induces systemic cytokine production and
DCs to induce maturation and cross priming of TAA-specific CTLs in lymphoid tissues during the priming phase (left panel). PD-1/PD-L1 blockade boosts ARNAX-mediated CTL induction in the priming phase and gives a boost to tumor-infiltrating CTLs in the effector phase (Fig. 3)

second, which facilitates activation of the acquired immune system. Many studies have been published which show that the RIG-I/MDA5/MAVS pathway generally contributes to cytokines production [58, 65], while TLR3/TICAM-1 pathway encourages activation of the acquired immune system [9, 63, 88]. Certainly, MAVS pathway activation results in induction of type I IFN which subordinately contributes to DC priming. Thus, RNA sensor stimulation is not the preliminary trigger for DC priming. The structure and physiochemical comparison of TLR3 agonists discussed above has been described in Table 3 .

\section{ARNAX and poly-IC}

ARNAX does not contribute to the activation of the MAVS pathway. It instigates cross presentation in DCs, triggering $\mathrm{T}$ cell response without the aid of RIG-I/MDA5 or producing cytokines $[62,70]$. Thus, $\mathrm{T}$ cell activation through DC priming occurs without any inflammation $[64,75]$. Contrary to ARNAX, poly-IC is involved in the activation of TLR3 as well as MDA5. Poly-IC works not only on immune cells but also cancer cells [89, 90]. Poly-IC causes more intricate environmental conditions when compared to ARNAX. Moreover, poly-IC might disturb both the inflammatory status of the macrophages and DC priming. Any interference with the inflammatory status of macrophages penetrated deeply in tumors can have both negative and positive effect on tumors [91, 92]. 


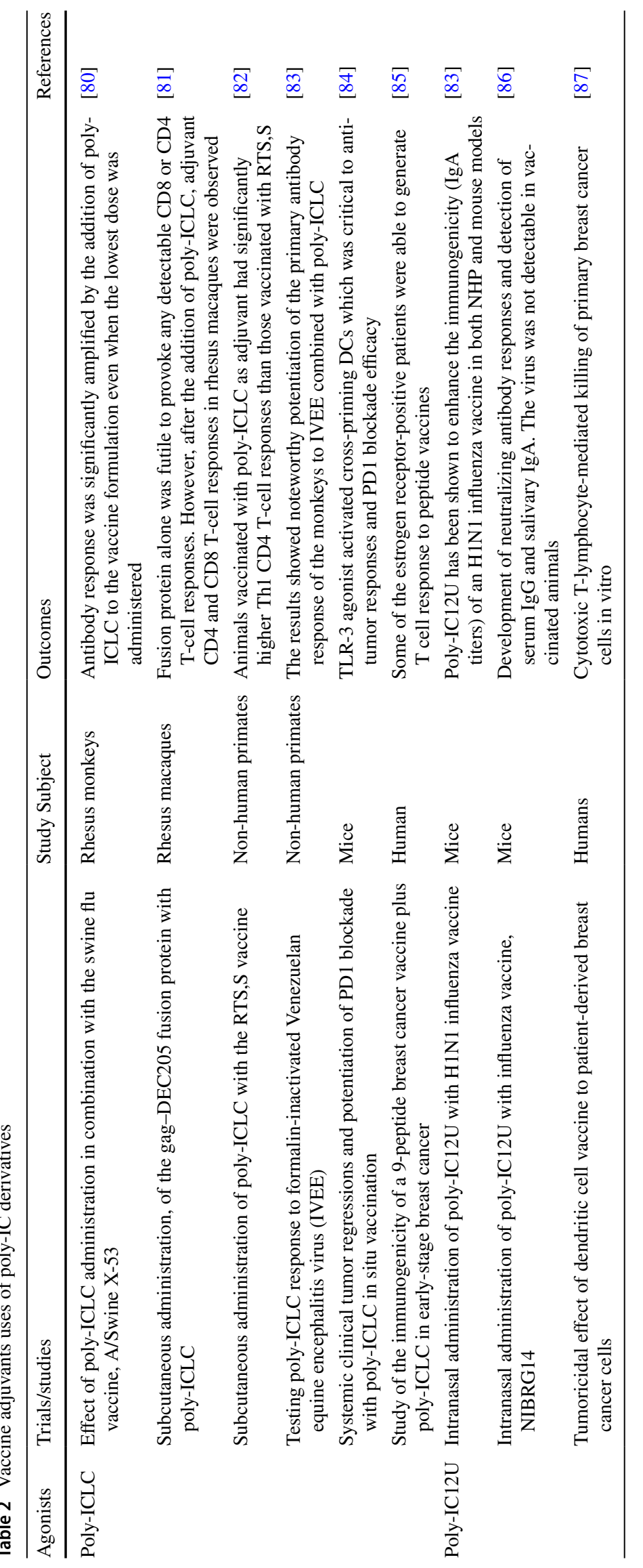


Table 3 Structural and physiochemical comparison [76]

\begin{tabular}{llll}
\hline & ARNAX & RGC100 & Poly-IC \\
\hline Size & $120 \sim 140 \mathrm{bp}$ & $100 \mathrm{bp}$ & $\sim 1500-8000 \mathrm{bp}$ \\
Molecular weight & & $64.6 \mathrm{KDa}$ & $\sim 1020-5440 \mathrm{KDa}$ \\
Structure & DNA-dsRNA & dsRNA & dsRNA \pm ssRNA \\
Serum stability & & Seven days & Less than 5 min \\
Agonists & TLR3 & TLR3 & TLR3, RLRs \\
\hline
\end{tabular}

\section{RGC100 and poly-IC}

The two characteristics of RGC100 such as good solubility and distinct chemical conformation play a significant role in reducing the potentially toxic effects of other TLR3 agonists, whereas, in case of poly-IC, its homogeneity plays a central role in the origin of toxicity. The heterogenic and polydisperse nature of poly-IC induces erratic pharmacokinetics [35].

The advantages of using RGC100 for instance, displaying distinct physicochemical characteristics such as solubility and homogeneity in addition to its specific chemical structure, molecular weight, and length, have previously been emphasized by others [35]. Another plus of RGC100 is its adeptness to calibrate its effectiveness for activation of immune cells by changing the size of the doublestranded RNA compound.

\section{Conclusion}

The three TLR3 agonists including RGC100, ARNAX and Poly-IC including their derivatives play a noteworthy role in tumor reduction through discrete cascades with each having its own benefits and challenges. The studies carried out in past do not provide adequate information to figure out the best among these since very limited comparative trials have been undertaken. Several clinical trials and comparative studies need to be performed to figure out the best agonist with maximum benefits and minimum side effect profile.

Funding The authors extend their appreciation to the Higher Education Commission (HEC) Islamabad, Pakistan for providing NRPU grant (No.10862) and deanship of scientific research at King Khalid University, Abha, Saudi Arabia, for funding this study under grant number (R.G.P2/122/42).

\section{Declarations}

Conflict of interest The authors declare that they have no conflict of interest.

\section{References}

1. Jimenez-Dalmaroni MJ, Gerswhin ME, Adamopoulos IE. The critical role of toll-like receptors-From microbial recognition to autoimmunity: a comprehensive review. Autoimmun Rev. 2016;15(1):1-8. https://doi.org/10.1016/j.autrev.2015.08.009.

2. Noreen M, Arshad M. Association of TLR1, TLR2, TLR4, TLR6, and TIRAP polymorphisms with disease susceptibility. Immunol Res. 2015;62(2):234-52. https://doi.org/10.1007/ s12026-015-8640-6.

3. Mahla RS, Reddy CM, Prasad D, Kumar H. Sweeten PAMPs: role of sugar complexed PAMPs in innate immunity and vaccine biology. Front Immunol. 2013;4:248.

4. Noreen M, Shah MA, Mall SM, Choudhary S, Hussain T, Ahmed I, et al. TLR4 polymorphisms and disease susceptibility. Inflamm Res. 2012;61(3):177-88. https://doi.org/10.1007/ s00011-011-0427-1.

5. Takeda K, Kaisho T, Akira S. Toll-like receptors. Annu Rev Immunol. 2003;21(1):335-76. https://doi.org/10.1146/annurev. immunol.21.120601.141126.

6. Matsumoto M, Seya T. TLR3: interferon induction by double-stranded RNA including poly(I:C). Adv Drug Deliv Rev. 2008;60(7):805-12. https://doi.org/10.1016/j.addr.2007.11.005.

7. Salaun B, Zitvogel L, Asselin-Paturel C, Morel Y, Chemin K, Dubois C, et al. TLR3 as a biomarker for the therapeutic efficacy of double-stranded RNA in breast cancer. Can Res. 2011;71(5):1607-14. https://doi.org/10.1158/0008-5472. can-10-3490.

8. Bianchi F, Pretto S, Tagliabue E, Balsari A, Sfondrini L. Exploiting poly(I:C) to induce cancer cell apoptosis. Cancer Biol Ther. 2017;18(10):747-56. https://doi.org/10.1080/15384047.2017. 1373220.

9. Matsumoto M, Funami K, Tanabe M, Oshiumi H, Shingai M, Seto $\mathrm{Y}$, et al. Subcellular localization of toll-like receptor 3 in human dendritic cells. J Immunol. 2003;171(6):3154-62. https://doi.org/ 10.4049/jimmunol.171.6.3154.

10. Lundberg AM, Drexler SK, Monaco C, Williams LM, Sacre SM, Feldmann M, et al. Key differences in TLR3/poly I: C signaling and cytokine induction by human primary cells: a phenomenon absent from murine cell systems. Blood. 2007;110(9):3245-52. https://doi.org/10.1182/blood-2007-02-072934.

11. Tamassia N, Le Moigne V, Rossato M, Donini M, McCartney S, Calzetti F, et al. Activation of an immunoregulatory and antiviral gene expression program in poly(I:C)-transfected human neutrophils. J Immunol. 2008;181(9):6563-73. https://doi.org/10.4049/ jimmunol.181.9.6563.

12 Wesch D, Beetz S, Oberg HH, Marget M, Krengel K, Kabelitz D. Direct costimulatory effect of TLR3 ligand poly(I:C) on human gamma delta T lymphocytes. J Immunol (Baltimore, Md : 1950). 2006;176(3):1348-54. https://doi.org/10.4049/jimmunol.176.3. 1348.

13. Heinz S, Haehnel V, Karaghiosoff M, Schwarzfischer L, Muller M, Krause SW, et al. Species-specific regulation of Toll-like receptor 3 genes in men and mice. J Biol Chem. 2003;278(24):21502-9. https://doi.org/10.1074/jbc.M301476200.

14. Johnsen IB, Nguyen TT, Ringdal M, Tryggestad AM, Bakke O, Lien E, et al. Toll-like receptor 3 associates with c-Src tyrosine kinase on endosomes to initiate antiviral signaling. EMBO J. 2006;25(14):3335-46. https://doi.org/10.1038/sj.emboj.7601222.

15. Gay NJ, Gangloff M, Weber AN. Toll-like receptors as molecular switches. Nat Rev Immunol. 2006;6(9):693-8. https://doi.org/10. 1038/nri1916.

16. Oshiumi H, Okamoto M, Fujii K, Kawanishi T, Matsumoto M, Koike $\mathrm{S}$, et al. The TLR3/TICAM-1 pathway is mandatory for innate immune responses to poliovirus infection. J Immunol 
(Baltimore, Md : 1950). 2011;187(10):5320-7. https://doi.org/ 10.4049/jimmunol.1101503.

17. Abe Y, Fujii K, Nagata N, Takeuchi O, Akira S, Oshiumi H, et al. The toll-like receptor 3-mediated antiviral response is important for protection against poliovirus infection in poliovirus receptor transgenic mice. J Virol. 2012;86(1):185-94. https://doi.org/10.1128/jvi.05245-11.

18. Negishi H, Osawa T, Ogami K, Ouyang X, Sakaguchi S, Koshiba R, et al. A critical link between toll-like receptor 3 and type II interferon signaling pathways in antiviral innate immunity. Proc Natl Acad Sci USA. 2008;105(51):20446-51. https://doi.org/10.1073/pnas.0810372105.

19. Matsumoto M, Kikkawa S, Kohase M, Miyake K, Seya T. Establishment of a monoclonal antibody against human toll-like receptor 3 that blocks double-stranded RNA-mediated signaling. Biochem Biophys Res Commun. 2002;293(5):1364-9. https:// doi.org/10.1016/s0006-291x(02)00380-7.

20. Pirher N, Pohar J, Mancek-Keber M, Bencina M, Jerala R. Activation of cell membrane-localized toll-like receptor 3 by siRNA. Immunol Lett. 2017;189:55-63. https://doi.org/10. 1016/j.imlet.2017.03.019.

21. Itoh K, Watanabe A, Funami K, Seya T, Matsumoto M. The clathrin-mediated endocytic pathway participates in dsRNAinduced IFN- $\beta$ production. J Immunol. 2008;181(8):5522-9. https://doi.org/10.4049/jimmunol.181.8.5522.

22. Singh D, Qi R, Jordan JL, San Mateo L, Kao CC. The human antimicrobial peptide LL-37, but not the mouse ortholog, mCRAMP, can stimulate signaling by poly(I:C) through a FPRL1-dependent pathway. J Biol Chem. 2013;288(12):825868. https://doi.org/10.1074/jbc.M112.440883.

23. Watanabe A, Tatematsu M, Saeki K, Shibata S, Shime H, Yoshimura A, et al. Raftlin is involved in the nucleocapture complex to induce poly(I:C)-mediated TLR3 activation. J Biol Chem. 2011;286(12):10702-11. https://doi.org/10.1074/jbc. M110.185793.

24. Yamashita M, Chattopadhyay S, Fensterl V, Saikia P, Wetzel JL, Sen GC. Epidermal growth factor receptor is essential for tolllike receptor 3 signaling. Sci Signal. 2012;5(233):ra50. https:// doi.org/10.1126/scisignal.2002581.

25. Chattopadhyay S, Sen GC. dsRNA-activation of TLR3 and RLR signaling: gene induction-dependent and independent effects. J Interferon Cytokine Res. 2014;34(6):427-36. https://doi.org/10. 1089/jir.2014.0034

26. Dunne A, O'Neill LA. Adaptor usage and toll-like receptor signaling specificity. FEBS Lett. 2005;579(15):3330-5. https://doi. org/10.1016/j.febslet.2005.04.024.

27. Takeda K, Akira S. TLR signaling pathways. Semin Immunol. 2004;16(1):3-9. https://doi.org/10.1016/j.smim.2003.10.003.

28. Jiang Z, Mak TW, Sen G, Li X. Toll-like receptor 3-mediated activation of NF-kappaB and IRF3 diverges at Toll-IL-1 receptor domain-containing adapter inducing IFN-beta. Proc Natl Acad Sci USA. 2004;101(10):3533-8. https://doi.org/10.1073/ pnas.0308496101.

29. Sasai M, Oshiumi H, Matsumoto M, Inoue N, Fujita F, Nakanishi $\mathrm{M}$, et al. Cutting Edge: NF-kappaB-activating kinaseassociated protein 1 participates in TLR3/Toll-IL-1 homology domain-containing adapter molecule-1-mediated IFN regulatory factor 3 activation. J Immunol. 2005;174(1):27-30. https://doi. org/10.4049/jimmunol.174.1.27.

30. Meylan E, Burns K, Hofmann K, Blancheteau V, Martinon $\mathrm{F}$, Kelliher M, et al. RIP1 is an essential mediator of toll-like receptor 3-induced NF-kappa B activation. Nat Immunol. 2004;5(5):503-7. https://doi.org/10.1038/ni1061.

31. Cusson-Hermance N, Khurana S, Lee TH, Fitzgerald KA, Kelliher MA. Rip1 mediates the Trif-dependent toll-like receptor 3- and 4-induced NF-\{kappa\}B activation but does not contribute to interferon regulatory factor 3 activation. J Biol Chem. 2005;280(44):36560-6. https://doi.org/10.1074/jbc.M5068 31200 .

32. Moser B, Hochreiter B, Basilio J, Gleitsmann V, Panhuber A, Pardo-Garcia A, et al. The inflammatory kinase IKKalpha phosphorylates and stabilizes c-Myc and enhances its activity. Mol Cancer. 2021;20(1):16. https://doi.org/10.1186/ s12943-021-01308-8.

33. Fitzgerald KA, McWhirter SM, Faia KL, Rowe DC, Latz E, Golenbock DT, et al. IKKepsilon and TBK1 are essential components of the IRF3 signaling pathway. Nat Immunol. 2003;4(5):491-6. https://doi.org/10.1038/ni921.

34. Kang J, Demaria S, Formenti S. Current clinical trials testing the combination of immunotherapy with radiotherapy. J Immunother Cancer. 2016;4:51. https://doi.org/10.1186/s40425-016-0156-7.

35. Le Noci V, Tortoreto M, Gulino A, Storti C, Bianchi F, Zaffaroni $\mathrm{N}$, et al. Poly(I:C) and CpG-ODN combined aerosolization to treat lung metastases and counter the immunosuppressive microenvironment. Oncoimmunology. 2015;4(10):e1040214. https://doi. org/10.1080/2162402x.2015.1040214.

36. Le Noci V, Sommariva M, Tortoreto M, Zaffaroni N, Campiglio $\mathrm{M}$, Tagliabue E, et al. Reprogramming the lung microenvironment by inhaled immunotherapy fosters immune destruction of tumor. Oncoimmunology. 2016;5(11):e1234571. https://doi.org/10.1080/ $2162402 x .2016 .1234571$.

37. Shime H, Matsumoto M, Oshiumi H, Tanaka S, Nakane A, Iwakura Y, et al. Toll-like receptor 3 signaling converts tumorsupporting myeloid cells to tumoricidal effectors. Proc Natl Acad Sci USA. 2012;109(6):2066-71. https://doi.org/10.1073/pnas. 1113099109.

38. Estornes Y, Micheau O, Renno T, Lebecque S. Dual role of TLR3 in inflammation and cancer cell apoptosis. 2013.

39. Jelinek I, Leonard JN, Price GE, Brown KN, Meyer-Manlapat A, Goldsmith PK, et al. TLR3-specific double-stranded RNA oligonucleotide adjuvants induce dendritic cell cross-presentation, CTL responses, and antiviral protection. J Immunol. 2011;186(4):2422-9. https://doi.org/10.4049/jimmunol.1002845.

40. Naumann K, Wehner R, Schwarze A, Petzold C, Schmitz M, Rohayem J. Activation of dendritic cells by the novel toll-like receptor 3 agonist RGC100. Clin Dev Immunol. 2013;2013:283649. https://doi.org/10.1155/2013/283649.

41. Conte MR, Conn GL, Brown T, Lane AN. Conformational properties and thermodynamics of the RNA duplex r(CGCAAAUUU GCG)2: comparison with the DNA analogue d(CGCAAATTT GCG)2. Nucleic Acids Res. 1997;25(13):2627-34. https://doi.org/ 10.1093/nar/25.13.2627.

42. Elmen J, Thonberg H, Ljungberg K, Frieden M, Westergaard $\mathrm{M}, \mathrm{Xu}$ Y, et al. Locked nucleic acid (LNA) mediated improvements in siRNA stability and functionality. Nucleic Acids Res. 2005;33(1):439-47. https://doi.org/10.1093/nar/gki193.

43. Bumcrot D, Manoharan M, Koteliansky V, Sah DW. RNAi therapeutics: a potential new class of pharmaceutical drugs. Nat Chem Biol. 2006;2(12):711-9. https://doi.org/10.1038/nchembio839.

44. Charles A, Janeway J, Medzhitov R. Innate immune recognition. Annu Rev Immunol. 2002;20(1):197-216. https://doi.org/10. 1146/annurev.immunol.20.083001.084359.

45. Tissari J, Siren J, Meri S, Julkunen I, Matikainen S. IFN-alpha enhances TLR3-mediated antiviral cytokine expression in human endothelial and epithelial cells by up-regulating TLR3 expression. J Immunol. 2005;174(7):4289-94. https://doi.org/10.4049/jimmu nol.174.7.4289.

46. Yoneyama M, Kikuchi M, Natsukawa T, Shinobu N, Imaizumi T, Miyagishi M, et al. The RNA helicase RIG-I has an essential function in double-stranded RNA-induced innate antiviral responses. Nat Immunol. 2004;5(7):730-7. https://doi.org/10.1038/ni1087. 
47. Kawai T, Akira S. Toll-like receptor and RIG-I-like receptor signaling. Ann N Y Acad Sci. 2008;1143:1-20. https://doi.org/10. 1196/annals.1443.020.

48. Chin AI, Miyahira AK, Covarrubias A, Teague J, Guo B, Dempsey PW, et al. Toll-like receptor 3-mediated suppression of TRAMP prostate cancer shows the critical role of type I interferons in tumor immune surveillance. Can Res. 2010;70(7):2595603. https://doi.org/10.1158/0008-5472.can-09-1162.

49. Besch R, Poeck H, Hohenauer T, Senft D, Hacker G, Berking C, et al. Proapoptotic signaling induced by RIG-I and MDA-5 results in type I interferon-independent apoptosis in human melanoma cells. J Clin Investig. 2009;119(8):2399-411. https://doi.org/10. 1172/jci37155.

50. Hirabayashi K, Yano J, Inoue T, Yamaguchi T, Tanigawara K, Smyth GE, et al. Inhibition of cancer cell growth by polyinosinicpolycytidylic acid/cationic liposome complex: a new biological activity. Can Res. 1999;59(17):4325-33.

51. McBride S, Hoebe K, Georgel P, Janssen E. Cell-associated double-stranded RNA enhances antitumor activity through the production of type I IFN. J Immunol. 2006;177(9):6122-8. https:// doi.org/10.4049/jimmunol.177.9.6122.

52. Trumpfheller C, Caskey M, Nchinda G, Longhi MP, Mizenina O, Huang Y, et al. The microbial mimic poly IC induces durable and protective CD4+ T cell immunity together with a dendritic cell targeted vaccine. Proc Natl Acad Sci USA. 2008;105(7):2574-9. https://doi.org/10.1073/pnas.0711976105.

53. Kumar H, Koyama S, Ishii KJ, Kawai T, Akira S. Cutting edge: cooperation of IPS-1- and TRIF-dependent pathways in poly ICenhanced antibody production and cytotoxic $\mathrm{T}$ cell responses. J Immunol. 2008;180(2):683-7. https://doi.org/10.4049/jimmunol. 180.2.683.

54. Longhi MP, Trumpfheller C, Idoyaga J, Caskey M, Matos I, Kluger C, et al. Dendritic cells require a systemic type I interferon response to mature and induce CD4+ Th1 immunity with poly IC as adjuvant. J Exp Med. 2009;206(7):1589-602. https://doi.org/ 10.1084/jem.20090247.

55. Galluzzi L, Vacchelli E, Eggermont A, Fridman WH, Galon J, Sautes-Fridman C, et al. Trial watch: experimental toll-like receptor agonists for cancer therapy. Oncoimmunology. 2012;1(5):699716. https://doi.org/10.4161/onci.20696.

56. Aranda F, Vacchelli E, Obrist F, Eggermont A, Galon J, SautesFridman C, et al. Trial watch: toll-like receptor agonists in oncological indications. Oncoimmunology. 2014;3:e29179. https://doi. org/10.4161/onci.29179.

57. Grunberg-Manago M, Oritz PJ, Ochoa S. Enzymatic synthesis of nucleic acidlike polynucleotides. Science (New York, NY). 1955;122(3176):907-10. https://doi.org/10.1126/science.122. 3176.907.

58. Kato H, Takeuchi O, Mikamo-Satoh E, Hirai R, Kawai T, Matsushita K, et al. Length-dependent recognition of double-stranded ribonucleic acids by retinoic acid-inducible gene-I and melanoma differentiation-associated gene 5. J Exp Med. 2008;205(7):160110. https://doi.org/10.1084/jem.20080091.

59. Robinson RA, DeVita VT, Levy HB, Baron S, Hubbard SP, Levine AS. A phase I-II trial of multiple-dose polyriboinosicpolyribocytidylic acid in patieonts with leukemia or solid tumors. J Natl Cancer Inst. 1976;57(3):599-602. https://doi.org/10.1093/ jnci/57.3.599.

60. Soutschek J, Akinc A, Bramlage B, Charisse K, Constien R, Donoghue $\mathrm{M}$, et al. Therapeutic silencing of an endogenous gene by systemic administration of modified siRNAs. Nature. 2004;432(7014):173-8. https://doi.org/10.1038/nature03121.

61. Martins KA, Bavari S, Salazar AM. Vaccine adjuvant uses of poly-IC and derivatives. Expert Rev Vaccines. 2015;14(3):44759. https://doi.org/10.1586/14760584.2015.966085.
62. Seya T, Azuma M, Matsumoto M. Targeting TLR3 with no RIG-I/MDA5 activation is effective in immunotherapy for cancer. Expert Opin Ther Targets. 2013;17(5):533-44. https://doi. org/10.1517/14728222.2013.765407.

63. Matsumoto M, Tatematsu M, Nishikawa F, Azuma M, Ishii N, Morii-Sakai A, et al. Defined TLR3-specific adjuvant that induces NK and CTL activation without significant cytokine production in vivo. Nat Commun. 2015;6:6280. https://doi.org/ 10.1038/ncomms7280.

64. Matsumoto M, Takeda Y, Tatematsu M, Seya T. Toll-like receptor 3 signal in dendritic cells benefits cancer immunotherapy. Frontiers in Immunology. 2017;8(1897). https://doi.org/10. 3389/fimmu.2017.01897.

65. Kato H, Takeuchi O, Sato S, Yoneyama M, Yamamoto M, Matsui $\mathrm{K}$, et al. Differential roles of MDA5 and RIG-I helicases in the recognition of RNA viruses. Nature. 2006;441(7089):101.

66. Gitlin L, Barchet W, Gilfillan S, Cella M, Beutler B, Flavell $\mathrm{RA}$, et al. Essential role of mda-5 in type I IFN responses to polyriboinosinic: polyribocytidylic acid and encephalomyocarditis picornavirus. Proc Natl Acad Sci. 2006;103(22):8459-64.

67. Gerner MY, Heltemes-Harris LM, Fife BT, Mescher MF. Cutting edge: IL-12 and type I IFN differentially program CD8 T cells for programmed death 1 re-expression levels and tumor control. J Immunol. 2013;191(3):1011-5. https://doi.org/10. 4049/jimmunol.1300652.

68. Funami K, Matsumoto M, Obuse C, Seya T. 14-3-3-zeta participates in TLR3-mediated TICAM-1 signal-platform formation. Mol Immunol. 2016;73:60-8. https://doi.org/10.1016/j.molimm. 2016.03.010.

69. Takeda Y, Takaki H, Fukui-Miyazaki A, Yoshida S, Matsumoto M, Seya T. Vaccine adjuvant ARNAX promotes mucosal IgA production in influenza HA vaccination. Biochem Biophys Res Commun. 2018;506(4):1019-25. https://doi.org/10.1016/j.bbrc. 2018.10.166.

70. Takeda Y, Kataoka K, Yamagishi J, Ogawa S, Seya T, Matsumoto M. A TLR3-specific adjuvant relieves innate resistance to PD-L1 blockade without cytokine toxicity in tumor vaccine immunotherapy. Cell Rep. 2017;19(9):1874-87.

71. Zevini A, Olagnier D, Hiscott J. Crosstalk between cytoplasmic RIG-I and STING sensing pathways. Trends Immunol. 2017;38(3):194-205.

72. Fuertes MB, Kacha AK, Kline J, Woo S-R, Kranz DM, Murphy $\mathrm{KM}$, et al. Host type I IFN signals are required for antitumor CD8+ T cell responses through CD8 $\alpha+$ dendritic cells. J Exp Med. 2011;208(10):2005-16.

73. Pantel A, Teixeira A, Haddad E, Wood EG, Steinman RM, Longhi MP. Direct type I IFN but not MDA5/TLR3 activation of dendritic cells is required for maturation and metabolic shift to glycolysis after poly IC stimulation. PLoS Biol. 2014;12(1):e1001759.

74. Matsumoto M, Takeda Y, Tatematsu M, Seya T. Toll-like receptor 3 signal in dendritic cells benefits cancer immunotherapy. Front Immunol. 2017;8:1897. https://doi.org/10.3389/fimmu.2017. 01897.

75. Seya T, Takeda Y, Takashima K, Yoshida S, Azuma M, Matsumoto M. Adjuvant immunotherapy for cancer: both dendritic cell-priming and check-point inhibitor blockade are required for immunotherapy. Proc Jpn Acad Ser B Phys Biol Sci. 2018;94(3):153-60. https://doi.org/10.2183/pjab.94.011.

76 Naumann K, Wehner R, Schwarze A, Petzold C, Schmitz M, Rohayem J. Activation of dendritic cells by the novel toll-like receptor 3 agonist RGC100. Clin Dev Immunol. 2013;2013:283649. https://doi.org/10.1155/2013/283649.

77. Seya T, Takeda Y, Matsumoto M. A toll-like receptor 3 (TLR3) agonist ARNAX for therapeutic immunotherapy. Adv Drug Deliv Rev. 2019;147:37-43. https://doi.org/10.1016/j.addr.2019.07.008. 
78. Stahl-Hennig C, Eisenblätter M, Jasny E, Rzehak T, Tenner-Racz $\mathrm{K}$, Trumpfheller C, et al. Synthetic double-stranded RNAs are adjuvants for the induction of $\mathrm{T}$ helper 1 and humoral immune responses to human papillomavirus in rhesus macaques. PLoS Pathog. 2009;5(4):e1000373. https://doi.org/10.1371/journal.ppat. 1000373.

79. Park H, Adamson L, Ha T, Mullen K, Hagen SI, Nogueron A, et al. Polyinosinic-polycytidylic acid is the most effective TLR adjuvant for SIV Gag protein-induced T cell responses in nonhuman primates. J Immunol. 2013;190(8):4103-15. https://doi.org/ 10.4049/jimmunol.1202958.

80. Stephen EL, Hilmas DE, Mangiafico JA, Levy HB. Swine influenza virus vaccine: potentiation of antibody responses in rhesus monkeys. Science. 1977;197(4310):1289-90. https://doi.org/10. 1126/science.408923.

81. Flynn BJ, Kastenmüller K, Wille-Reece U, Tomaras GD, Alam M, Lindsay RW, et al. Immunization with HIV Gag targeted to dendritic cells followed by recombinant New York vaccinia virus induces robust T-cell immunity in nonhuman primates. Proc Natl Acad Sci U S A. 2011;108(17):7131-6. https://doi.org/10.1073/ pnas. 1103869108

82. Kastenmüller K, Espinosa DA, Trager L, Stoyanov C, Salazar AM, Pokalwar S, et al. Full-length plasmodium falciparum circumsporozoite protein administered with long-chain poly(I.C) or the toll-like receptor 4 agonist glucopyranosyl lipid adjuvant-stable emulsion elicits potent antibody and CD4+ T cell immunity and protection in mice. Infect Immun. 2013;81(3):789-800. https:// doi.org/10.1128/iai.01108-12.

83. Houston WE, Crabbs CL, Stephen EL, Levy HB. Modified polyriboinosinic-polyribocytidylic acid, an immunological adjuvant. Infect Immun. 1976;14(1):318-9. https://doi.org/10.1128/iai.14.1. 318-319.1976.

84. Hammerich L, Marron TU, Upadhyay R, Svensson-Arvelund J, Dhainaut M, Hussein S, et al. Systemic clinical tumor regressions and potentiation of PD1 blockade with in situ vaccination. Nat Med. 2019;25(5):814-24. https://doi.org/10.1038/ s41591-019-0410-x.

85. Dillon PM, Petroni GR, Smolkin ME, Brenin DR, Chianese-Bullock KA, Smith KT, et al. A pilot study of the immunogenicity of a 9-peptide breast cancer vaccine plus poly-ICLC in early stage breast cancer. J Immunother Cancer. 2017;5(1):92. https://doi.org/ 10.1186/s40425-017-0295-5.
86. Ichinohe T, Ainai A, Ami Y, Nagata N, Iwata N, Kawaguchi A, et al. Intranasal administration of adjuvant-combined vaccine protects monkeys from challenge with the highly pathogenic influenza A H5N1 virus. J Med Virol. 2010;82(10):1754-61. https:// doi.org/10.1002/jmv.21824.

87. Tomasicchio M, Semple L, Esmail A, Meldau R, Randall P, Pooran A, et al. An autologous dendritic cell vaccine polarizes a Th-1 response which is tumoricidal to patient-derived breast cancer cells. Cancer Immunol Immunother. 2019;68(1):71-83. https://doi.org/10.1007/s00262-018-2238-5.

88. Azuma M, Ebihara T, Oshiumi H, Matsumoto M, Seya T. Crosspriming for antitumor CTL induced by soluble $\mathrm{Ag}+$ polyI: C depends on the TICAM-1 pathway in mouse CD11c $(+) / C D 8 \alpha(+)$ dendritic cells. Oncoimmunology. 2012;1(5):581-92. https://doi. org/10.4161/onci.19893.

89. Dunn GP, Koebel CM, Schreiber RD. Interferons, immunity and cancer immunoediting. Nat Rev Immunol. 2006;6(11):836-48. https://doi.org/10.1038/nri1961.

90. Shime H, Maruyama A, Yoshida S, Takeda Y, Matsumoto M, Seya T. Toll-like receptor 2 ligand and interferon-gamma suppress anti-tumor $\mathrm{T}$ cell responses by enhancing the immunosuppressive activity of monocytic myeloid-derived suppressor cells. Oncoimmunology. 2017;7(1):e1373231. https://doi.org/10.1080/ 2162402x.2017.1373231.

91. Gupta SK, Yadav PK, Tiwari AK, Gandham RK, Sahoo AP. Poly (I:C) enhances the anti-tumor activity of canine parvovirus NS1 protein by inducing a potent anti-tumor immune response. Tumour Biol. 2016;37(9):12089-102. https://doi.org/10.1007/ s13277-016-5093-z.

92 Medrano RFV, Hunger A, Mendonça SA, Barbuto JAM, Strauss BE. Immunomodulatory and antitumor effects of type I interferons and their application in cancer therapy. Oncotarget. 2017;8(41):71249-84. https://doi.org/10.18632/oncotarget.19531.

Publisher's note Springer Nature remains neutral with regard to jurisdictional claims in published maps and institutional affiliations. 